\title{
Teologia e direitos humanos: um diálogo interdisciplinar entre Tomás de Aquino e Paulo Freire na perspectiva da consciência
}

\author{
Theology and human rights: an interdisciplinary \\ dialogue between Thomas Aquinas and Paulo \\ Freire in the perspective of conscience
}

\section{Andre Boccato Almeida*}

Pontifícia Universidade Católica de São Paulo, São Paulo, SP, Brasil

Centro Universitário Salesiano de São Paulo, São Paulo, SP, Brasil

\section{Resumo}

O presente artigo propõe-se a refletir de forma interdisciplinar o tema da teologia e direitos humanos a partir dos dois pensadores: um teólogo italiano e um pedagogo brasileiro. Em seus contextos, ambos propuseram uma pertinente e relevante reflexão sobre o ensino e a educação. Em tempos como os nossos, nos quais os valores éticos tendem a ser banalizados pelo bombardeio de imagens simuladas, informações construídas e versões da verdade segundo interpretações ideológicas, estes dois pensadores, cada um em seu horizonte de mundo, convidam-nos a voltar ao sentido último do ato educativo: refletir, pensar e buscar o sentido da verdade. Nas respectivas

*ABA: Doutor em Teologia, e-mail: a.I.boccato@gmail.com 
propostas teóricas, éticas e pedagógicas, encontra-se o gérmen inspirador da consciência, base dos diretos humanos.

Palavras-chave: Teologia. Direitos Humanos. Consciência. Tomás de Aquino. Paulo Freire.

\section{Abstract}

The present article proposes to reflect in an interdisciplinary way the theme of theology and human rights from the two thinkers: an Italian theologian and a Brazilian pedagogue. In their contexts, both proposed a pertinent and relevant reflection on teaching and education. In times like ours, in which ethical values tend to be trivialized by a bombardment of simulated images, constructed information and versions of truth according to ideological interpretations, these two thinkers, each on their world horizon, invite us to return to the ultimate meaning of the act educational: reflect, think and seek the meaning of truth. In the respective theoretical, ethical and pedagogical proposals, lies the inspiring germ of consciousness, the basis of human directness.

Keywords: Theology. Human rights. Consciousness. Thomas Aquinas. Paulo Freire.

\section{Introdução}

A presente reflexão, de natureza interdisciplinar, pretende estabelecer um diálogo propositivo entre a sabedoria teológica e os direitos humanos. Para isso, procurar-se-á fundamentar este escopo articulando dois pensadores, distantes no tempo e no espaço, mas próximos em suas intuições humanistas: Tomás de Aquino e Paulo Freire. Ambos erigiram seus pensamentos em uma visão positiva e ética de ser humano: Tomás, teólogo, a partir do constante confronto entre a tradição bíblica e a reflexão filosófica aristotélica, superando uma visão que ultrapassasse uma ótica autoritária pela racionalidade reflexiva; Paulo Freire, educador e filósofo, em sua gradual percepção de educação e ensino que visava conscientizar 
os educandos a partir da capacidade de pensamento presente nas camadas de opressão da consciência.

Em Tomás de Aquino, ilustre teólogo dominicano, comentador das Escrituras e também mestre no contexto do surgimento das universidades, encontramos uma sólida proposta de ensino que, para além de propor conteúdos à pessoa, apontou a verdade interior a ser compreendida em sua integralidade pelo sujeito. Em sua obra De Magistro (TOMÁS DE AQUINO, 2004), inserida como uma das questões disputadas sobre a verdade (a de $n^{\circ} 11$ ), apresenta com profundidade sua visão dialógica ("dialética") do ser humano que busca a verdade mediante um processo de ensino gradual, pertinente a nós que vivemos em meio à cultura de excesso de informações (CASTELLS, 2013, p. 128-133) nem sempre refletidas na consciência do sujeito ético. Paulo Freire, filósofo e pedagogo brasileiro, crítico de um sistema educacional que se reduzia a adequar as consciências dos alunos ao modelo de sociedade desigual, em um modelo de "educação bancária" (FREIRE, 1975b, p. 67), pode ser continuamente estudado e descoberto como um original educador que conduziu o aluno ou educando à uma emancipação de sua consciência, de sua subjetividade antes oprimida, a um lento processo de tornar-se sujeito mediante a palavra pronunciada em relação afetiva com o objeto representado.

Tanto Aquino como Freire são autores que ainda hoje exigem uma contínua revisitação em seus pensamentos. $O$ intento neste artigo é captar a possível relação entre teologia - reflexão crítica e sistemática da fé - com o tema dos direitos humanos. Parte-se da hipótese de que nas duas configurações "educacionais" podem ser encontradas preocupações humanistas - próprias dos direitos humanos - , pois, por serem educadores e mestres no ensino, empenhavam-se em fazer aflorar a originalidade de cada pessoa, contrariamente aos desumanismos próprios de seus tempos. Essa possibilidade encontra no tema da consciência sua condição de encontro e nos direitos humanos um diálogo válido. 


\section{O ensino e a educação em Tomás de Aquino}

O tema do ensino e da educação no teólogo Tomás de Aquino (dito Aquinate), embora pouco aprofundado ou estudado de forma precisa, ocupa um lugar central no seu pensamento, pois por ter sido um pregador itinerante, mestre em Sacra Pagina - comentador das Escrituras - era um professor, um verdadeiro mestre da fé e da teologia; portanto, era alguém dedicado ao estudo, sua transmissão e a recepção por parte dos seus alunos. A educação, ou o ensino, no contexto medieval, era colocada de modo distinto da percepção contemporânea; esta é mais focada em métodos que auxiliam na absorção de ideias, conhecimentos e percepções a serem assumidas pelo aluno (MORIN, 1999, p. 22). A perspectiva medieval e escolástica, própria do tempo de São Tomás ${ }^{1}$, colocava-se em um horizonte de disputas ou questões a serem esclarecidas por meio de debates acadêmicos.

Na verdade, o contexto do século XIII é o das nascentes universidades e corporações. Em cada cidade existia um ofício agrupando um número importante de membros. Esses se organizavam para a defesa de seus interesses e a instauração de um monopólio de que se beneficiassem. Era a fase institucional do impulso urbano que se materializava em comunas, onde as liberdades políticas eram conquistadas; nestas corporações, as posições adquiridas advinham fortemente do domínio econômico (LE GOFF, 2003, p. 93) que ressurgia lentamente. Tomás vivia este momento de renascimento das cidades e das universidades no contexto de sua vida e futuras decisões, ou seja,

Tomás de Aquino nasce em 1224, no mesmo ano da fundação da Universidade de Nápoles, na qual se matriculou bem jovem, por volta dos catorze anos. Bem se poderia ilustrar essa primeira opção e a primeira caminhada do menino e do jovem, realçando o simbolismo dos monumentos que balizam seu avanço na vida: criança de uns três anos, acompanhado de sua babá, o pequeno Tomás deixa o castelo de Rocassecca, em que nascera, e é levado ao grande e famoso mosteiro beneditino de Monte

1 Para Mondin (2013, p. 17-18), no tempo do Aquinate, perguntar-se sobre o ser e a verdade das coisas era 0 "espírito" da época, o que impulsionou a buscar a verdade e a essência do ensino e da educação em debates longos e no diálogo com visões distintas.

Rev. Pistis Prax., Teol. Pastor., Curitiba, v. 11, n. 1, 077-096, jan./abr. 2019 
Cassino. Lá aprende a rezar e a estudar no quadro religioso da escola monástica. Mas desde que atinge a precoce idade acadêmica de então, percebe que sua família anda às voltas com a política e lhe consente espaços de liberdade. Vai então estudar na Universidade do Imperador Frederico II, em Nápoles, a mais aberta às inovações filosóficas. E [...] acaba indo morar numa simples casa religiosa dos frades dominicanos que frequentavam a universidade segundo as orientações de seu fundador, São Domingos (JOSAPHAT, 2016, p. 52-53).

De Nápoles, os dominicanos não consideraram seguro conservar consigo o novo jovem e o enviaram a Roma, onde se decidiria o seu futuro, designando-o a alguma universidade a fim de que prosseguisse seus estudos. De Roma foi a Paris e posteriormente a Colônia, onde florescia o studium generale, sob a direção do irmão Alberto, mestre em teologia, e reputado erudito em todos os domínios do saber (TORREL, 2004, p. 2324). De volta a Paris, no segundo período de ensino (1268-1272), Tomás dedicou-se principalmente ao ensino da Sacra Pagina, com os vários comentários bíblicos, tendo ali também dado continuidade a uma série de questões disputadas que marcarão sua presença na Universidade. Há várias Quaestiones Disputatae de Veritate entre 1256 a 1259. Da primeira regência (1256-1257) há sete questões importantes, tais como: sobre a verdade, o conhecimento de Deus, as ideias divinas, o verbum, a providência divina, a predestinação e o "livro da vida".

De 1257 a 1258 há outras 13 questões, tais como: sabedoria evangélica, comunicação evangélica, a mente como imagem da Trindade, o ensino, a profecia como sabedoria, o êxtase, a fé, a razão superior e a inferior, a sindérese, a consciência, o conhecimento de Adão no Paraíso, o conhecimento da alma depois da morte e o conhecimento de Cristo nesta vida. Enfim, de 1258 a 1259 havia nove questões: a bondade, o desejo do bem e a vontade, a vontade de Deus, o livre-arbítrio, o apetite dos sentidos, as paixões humanas, a graça, a justificação do pecador e a graça da alma de Cristo (TOMÁS DE AQUINO, 2004, p. 3). São Tomás trata do ensino na questão disputada (Questione Disputatae) chamada "Sobre a verdade" ("De Veritate") em sua segunda estadia em Paris. Ela integrava a própria essência da educação escolástica, pois não era suficiente escutar a exposição dos grandes livros do pensamento ocidental por um mestre; 
era essencial que as grandes ideias fossem examinadas criticamente na disputa (WEISHEIPL, 1994, p. 235).

Pode-se conhecer a verdade, mas não se pode dirimi-la simplesmente. São Tomás - como é próprio do seu método - dá ao adversário da disputa a possibilidade de, com honestidade e rigor próprios, apresentar sua visão sobre a verdade. Diante deste cenário de ensino riquíssimo em que Tomás de Aquino foi gerado e com que também contribuiu, emanam várias questões e, dentre elas, a do ensino, De Magistro ${ }^{2}$. Esta quaestio disputata encontra-se no contexto da quaestio mais abrangente De Veritate. O De Magistro pode ser considerado a obra mais próxima ao problema do ensino e da problemática educativa. Esta quaestio está organizada por ele em quatro artigos: 1 . Se o homem - ou somente Deus - pode ensinar e ser chamado mestre ("Utrum homo possit docere et dici magister, vel solus Deus"); 2. Se se pode dizer que alguém é mestre de si mesmo ("Utrum aliquis possit dici magister sui ipsius"); 3. Se o homem pode ser ensinado por um anjo ("Utrum homo ab angelo doceri possit"); 4. Se ensinar é um ato da vida ativa ou da vida contemplativa ("Utrum docere sit actus vitae contemplativae, vel activae").

Com as quaestio disputatae em geral, e a sobre o ensino em particular, avista-se em São Tomás o produto realizado do pensamento escolástico (filosófico ou teológico), bem como com o trabalho mais rico de seu gênio pessoal. A questão disputada era o fruto maduro da evolução da técnica intelectual da Universidade ${ }^{3}$ e, para o teólogo, o ponto mais ousado da atividade da razão em uma fé que, para se solidificar, estava disposta a se "questionar" em si mesma (CHENU, 1954, p. 241).

O De Magistro de Tomás de Aquino expõe sua concepção de ensino/ aprendizagem em oposição às doutrinas dominantes da época, principalmente a uma tendência de um cristianismo demasiadamente espiritualista que pretendia exagerar o papel de Deus e aniquilar a criatura (LAUAND,

2 Cf. THOMAEAQUINATIS, 1964, p. 223-233. Usaremos tanto esta edição na língua latina como também o texto em língua portuguesa que se encontra na bibliografia.

3 Cf. VERGER, J. Universidade. In: LE GOFF; SCHIMITT, 2006, p. 573-587. Neste verbete, o autor faz uma sugestiva análise histórica do surgimento da universidade e dos movimentos acadêmicos com as disputas próprias do seu contexto medieval. Situa-se de forma sintética o papel das ordens mendicantes no progresso do ensino e educação com os conflitos existentes nesta época.

Rev. Pistis Prax., Teol. Pastor., Curitiba, v. 11, n. 1, 077-096, jan./abr. 2019 
2004, p. 6). Segundo Colombu, o De Magistro de São Tomás é a única obra da Escolástica na qual se busca resolver, de modo especulativo-sistemático, o problema proposto pelo bispo de Hipona - Santo Agostinho segundo o qual Cristo é o único docente (Christus docens). Para ele, a luz divina que ilumina a interioridade é a mesma luz da razão que Deus infunde em cada homem no ato da criação, ou, como diria Aristóteles, a luz do intelecto ativo (COLOMBU, 1974, p. 426-427).

Na Idade Média, esta tese tinha sido motivo de disputas e interpretações, além de ser desenvolvida por várias correntes, doutrinas ou tendências ${ }^{4}$. Muitas destas visões acreditavam no fato de que não haveria necessidade de educação ou a existência de um mestre educador, porque o homem seria munido já em sua natureza de tudo o que lhe ocorresse. Tomás, segundo Mondin, replicava que a natureza certamente deu ao homem uma predisposição ao estudo, ao trabalho e à virtude, mas a perfeição destas atividades precisava ser desenvolvida e praticada, como uma virtude, para que se buscasse a verdade e aprimorasse a sua consciência (MONDIN, 1991, p. 210).

Para Tomás de Aquino, o mais importante, por meio desta quaestio sobre o ensino, era afirmar uma visão positiva de ser humano - uma antropologia filosófica - que acentuava o homem em sua totalidade (o espírito integrado à matéria), evitando certo exagero de uma visão ou iluminação provinda imediatamente de Deus, próprio das correntes de pensamento de sua época. A iluminação, na verdade, Deus já concedeu ao ser humano quando o dotou pela racionalidade; contudo, é propriamente o exercício desta racionalidade em sua integridade que era defendida por ele em uma perspectiva de virtude ou pedagogia a ser aprendida e desenvolvida.

Convém recordar que para o teólogo dominicano a conquista de cada verdade parcial, mediante um processo de ensino e educação, conduz

4 Cf. Sobre estas correntes, doutrinas ou tendências há uma análise histórico-crítica feita por WEISHEIPL, 1993, p. 293-302, no subcapítulo intitulado “Nouvelles oppositions aux mendiants”. 
à única Verdade, de modo que se entrega àquelas para alcançar esta ${ }^{5}$. Assim, se abrem na mente - próprio de um teólogo que se aventura na nascente academia - muitos espaços infinitos.

O Aquinate foi herdeiro de um horizonte educacional mais antigo que estabelecia um vínculo entre o sujeito que ensina e o sujeito que aprende e se propõe a dar uma interpretação, que vinha desde a antiguidade com Sócrates e Platão, passando pelas soluções agostinianas e de Avicena (GRANDINETTI, 1974, p. 464). Desta preocupação em valorizar o sujeito, destacando a sua responsabilidade em buscar não apenas o conhecimento, mas o próprio desdobramento de suas capacidades, é que encontramos em Tomás a preocupação em formar a consciência e a subjetividade do próprio homem ${ }^{6}$.

A sociedade do século XIII, de seu tempo, se apresentava fortemente estruturada em torno do papado e do império cristão. Depois de profundas transformações, a Europa ocidental tinha conseguido formar uma sociedade na qual a ordem política estava garantida e era estável o marco da cristandade (LUENGO, 1999, p. 38). O cristianismo de sua época, herdeiro de formas religiosas originais e assimilador de modos humanos evoluídos, tinha criado sua própria sociedade. Este era, propriamente em poucas palavras, o contexto sociopolítico de Tomás de Aquino. Sua percepção de educação, consciência e direito advinha de uma mudança de mundo e sociedade.

Seu pensamento sobre a educação estava, portanto, situado no contexto de cristandade com suas emergentes questões em torno do ser humano emancipado de um modelo de cultura em mutação. Se quisesse salvar a fé, era necessário afrontar os diversos âmbitos sociais, culturais e religiosos de forma nova. Embora a ideia de direitos humanos como

5 Em Tomás de Aquino, o ensino, a moral e a virtude são indissociáveis. Embora o tema vá além da questão disputada De Magistro, o aperfeiçoamento da vida humana constitui a essência da cultura no sentido dinâmico do termo. Para Bednarski (1986, p. 27-42), o fato de o homem buscar a verdade última que é Deus o coloca em um movimento de ter que organizar sua vida interior por meio de um processo educativo da própria afetividade e das paixões interiores.

6 Auer (1991, p. 124-137), citando São Tomás, faz uma interessante análise histórico-teológica dos modelos de morais ocidentais, identificando na visão tomasiana de autonomia, em pleno século XIII, sua original ética das virtudes como formadora e educadora do sujeito universitário de sua época, e o posterior esquecimento de seu pensamento, substituído por um de caráter mais legalista e jurídico.

Rev. Pistis Prax., Teol. Pastor., Curitiba, v. 11, n. 1, 077-096, jan./abr. 2019 
compreende-se hoje não seja própria de sua época, Tomás já tentava articular em sua teologia as duas principais linhas teóricas e históricas diferentes: o direito natural e a ideia de liberdade ${ }^{7}$.

$\mathrm{Na}$ sua perspectiva de direito está presente uma busca por colocar no centro a dignidade da pessoa (MARITAIN, 1962, p. 65), mas compreendida na lógica própria do seu sistema teológico: a dignidade da pessoa humana não numa reivindicação de autonomia absoluta diante de Deus, mas na aceitação da dependência a ele (TORREL, 2008, p. 375). Em Tomás, o ser humano - criatura racional - participa da lei eterna, da Providência Divina. Esta participação se realiza por um habitus (sindérese). O desenvolvimento e aprimoramento deste mecanismo dá-se por meio de um processo educativo que é a formação do sujeito moral.

Para ele, o agente principal de cada aprendizado é o que aprende propriamente, e o mestre, a causa secundária. Este ajuda, colabora, estimula e guia, mas não é indispensável, pois o ideal de homem bem educado é o que é capaz de buscar ser intelectualmente independente ${ }^{8}$. O mestre com a sua ação e com o seu ensino verbal não cria o saber, pois este brota da interioridade do próprio aluno ajudado pelo mestre quando lhe possibilita ter acesso aos conceitos últimos.

Como para Tomás o ensino é inerente à condição moral do sujeito, em sua subjetividade em processo na consciência, todas as vezes que esta capacidade de ensino e aprendizado se desenvolve, significa que, em quem aprende, são geradas as determinações morais, isto é, os hábitos virtuosos ou as virtudes éticas. O aprendizado, neste sentido, forma os hábitos intelectuais ou cognoscitivos — ciência. Para nós, contemporâneos, esta perspectiva de ensino e educação - de teor mais filosófico - aparenta ser mais teórica que prática, contudo, São Tomás, com sua visão integral

7 Cf. COMPAGNONI, 1997, p. 222. Para São Tomás, tratava-se de esclarecer como a ideia de lei eterna - razão de Deus - está presente na razão do homem (Summa Theologiae I-II, q. 91, a. 2).

8 Esta sua tese pode ser comprovada no De Magistro a. 1, solutione. Ali, São Tomás desenvolve três perspectivas acerca do aprendizado. Na terceira, que ele chama de terceira via, diz que preexistem em todo ser humano certas sementes de saber que são os primeiros conceitos do intelecto. Desta, explicita as duas potências ativa e passiva -, dizendo que o conhecimento preexiste no educando de forma ativa, como uma descoberta, enquanto no ensino há o auxílio externo do professor. 
de pessoa, não a caracteriza apenas em sua perspectiva pragmática, mas acima de tudo segundo um prisma ontológico e dinâmico.

Constata-se que, para São Tomás, a moral e o ensino - isto é, o processo educacional — não são constituídos por um conjunto de normas que se impõem ao homem, determinado modo de comportamento com base no poder coercitivo da autoridade divina (COSTA, 1993, p. 113), mas exprime simplesmente o modo correto do agir humano segundo as exigências da razão.

Nesse sentido, a moral e o ensino têm por fundamento a ética ou filosofia moral, entendida como o conjunto de princípios racionais que orientam o homem na busca da felicidade. Por meio deste desenvolvimento e progresso da natureza humana a pessoa tem o mérito, em virtude de um esforço incessante, de desabrochar suas potencialidades, integrando as paixões internas e as inclinações externas ${ }^{9}$.

A visão de ensino e educação para São Tomás é um autêntico educar, isto é, "trazer para fora” e não "colocar para dentro". É propriamente um educar para as possibilidades e não domesticar segundo uma doutrina. Educar, para ele, pressupõe a liberdade de pensamento, um verdadeiro aprimoramento da capacidade de atingir o fim, isto é, a própria verdade da pessoa.

\section{0 ensino e a educação em Paulo Freire}

A educação em Paulo Freire é uma palavra-chave que identifica a sua vida e acompanhou todo o seu itinerário como educador e ser humano preocupado com a formação das consciências. O ensino e os processos de

90 tema das paixões em Santo Tomás (De passionibus) é um rico tratado ético-teológico que exigiria maiores aprofundamentos em diálogo com todos os avanços trazidos pelas ciências e as antropologias contemporâneas. Contudo, não podemos deixar de frisar que as paixões da alma, os afetos, as inclinações, os vícios, as virtudes e a integração mediante um processo educativo e virtuoso foram mais desenvolvidas na Summa Theologiae II-II (para esta referência, TOMÁS DE AQUINO, 2002). 
formação do sujeito — da subjetividade — estiveram entre as maiores buscas do pedagogo e filósofo brasileiro ${ }^{10}$.

O ensino e a educação em Freire nascem e se desenvolvem a partir da sua história de vida. Para ele, a educação devia ir além do mero aprendizado sistemático na escola. Falava em educação ou alfabetização social, isto é, da necessidade de o aluno conhecer, analisar e se apropriar também dos problemas sociais que o afligiam. Não via o processo educativo simplesmente como meio para dominar os padrões acadêmicos de escolarização ou para profissionalizar-se, mas como uma necessidade de engajamento ${ }^{11}$, ou seja, de estímulo para que o povo a participasse do seu processo de emersão na vida pública no todo social (BRANDÃO, 2005, p. 53).

O próprio Paulo assim expressa, em um livro dialógico, esta relação,

A alfabetização e a educação, de modo geral, são expressões culturais. Não se pode desenvolver um trabalho de alfabetização fora do mundo da cultura, porque a educação é, por si mesma, uma dimensão da cultura. Pareceme fundamental, porém, na prática educativa, que os educadores não apenas reconheçam a natureza cultural do seu fazer, mas também desafiem os educandos a fazer o mesmo reconhecimento. Reconhecer, contudo, a natureza cultural da educação não significa abençoar toda expressão cultural, mas reconhecer que a própria luta pela superação do que Amílcar Cabral chamava "fraquezas da cultura" passa pela assunção da própria fraqueza. Daí que a educação deva tomar a cultura que a explica, pelo menos

10 Jesus (2012, p. 43-61) faz uma interessante análise - provocadora e corajosa - acerca da herança pedagógica e filosófica do seu pensamento. Na p. 43, faz a seguinte constatação: “Paulo Freire pedagogo [...] não nos causa surpresa, estamos acostumados a identificar Freire como um dos grandes pedagogos do século XX. Já a segunda definição costuma ser vista com certa desconfiança, uma vez que o estudo da obra freireana não figura nos currículos dos cursos de filosofia [...]. Situação no mínimo curiosa. Por que um autor tão marcado pela filosofia (fenomenologia, existencialismo, personalismo, hegelianismo, marxismo, escolanovismo e o desenvolvimento do Instituto Superior de Estudos Brasileiros), e que possui um pensamento estruturado a partir de categorias filosóficas não é estudado nos cursos de filosofia? Por que esse pensador é tão pouco investigado filosoficamente mesmo nos cursos de pedagogia?".

${ }^{11}$ A ideia de engajamento no pensamento de Paulo Freire foi analisada de forma sintética e concisa por Andreola (2010, p. 148-149). Neste, o autor compreende que o termo "engajamento" influenciou Freire à medida que ele teve contato com o sentido francês presente em Jacques Maritain e em Emmanuel Mounier. Para ele, foi na época em que Mounier passou a exercer maior influência - nos grupos cristãos de esquerda europeus - foi superada pelo sentido de Maritain, muito mais visto num viés de "cristandade" que como “laicidade", mais próprio para Mounier. 
em parte, como objeto de uma cuidadosa compreensão, com o que a educação se questiona a si mesma. E quanto mais se questiona na cultura e na sociedade em que se dá, tanto mais vai se tornando claro que a cultura é uma totalidade atravessada por interesses de classe, por diferenças de classe, por gostos de classe (FREIRE; MACEDO, 1990, p. 33).

A sua visão de educação está em estreita relação com a ideia de consciência crítica, formadora e emancipadora da subjetividade do sujeito envolvido em processos humanos e sociais. As suas obras sobre o tema da consciência e conscientização exprimem um lento e contínuo amadurecimento sobre a sua visão de educação.

Eis suas principais obras sobre o tema da consciência e educação: Educação como prática da liberdade (FREIRE, 1975a); Pedagogia do oprimido (FREIRE, 1975b); Conscientização: teoria e prática da libertação. Uma introdução ao pensamento de Paulo Freire (FREIRE, 1980); Ação Cultural para a Liberdade e outros escritos (FREIRE, 1982); Educação e mudança (FREIRE, 1985); Medo e ousadia (FREIRE; SHOR, 1997) e Pedagogia da autonomia: saberes necessários à prática educativa (FREIRE, 2013).

Em Paulo Freire, a visão de educação advém da própria compreensão que ele tem de ser humano e de consciência, contribuindo para uma perspectiva sobre a formação da subjetividade ${ }^{12}$ a partir de uma ética humanista e emancipadora do sujeito. Na sua abordagem acerca do ensino e da educação é central o humanismo presente em seu pensamento, proveniente do seu contínuo contato epistemológico com uma visão dialética e fenomenológica (TORRES, 2014, p. 82).

Freire não repete as estruturas de pensamento da tradição filosófica centrada no sujeito, mas busca inovar a partir do desafio da realidade do oprimido, em diálogo com os instrumentos de análise da reflexão

12 Mizukami (1986, p. 85-103), analisando o específico da "abordagem sociocultural", percebe que esta preocupação de Freire com a cultura popular advém após a Segunda Guerra Mundial com o movimento de democratização da cultura. Eis por que, no todo da sua obra, o homem é o sujeito da educação, primeiro responsável pela formação da sua consciência. Ela se constrói, chegando a ser sujeito, na medida em que aquele integrado no seu contexto reflete sobre ele e como ele se compromete, tomando consciência da sua historicidade.

Rev. Pistis Prax., Teol. Pastor., Curitiba, v. 11, n. 1, 077-096, jan./abr. 2019 
teórica ${ }^{13}$. Foi da dialética e da fenomenologia que ele buscou vencer o relacionamento oposto entre teoria e práxis, superando o que não deve ser feito num nível idealista, ampliando sua visão sobre o ser humano e a educação.

As três características ou expressões criadas por ele sobre o ser humano - ser mais, ser inacabado e sujeito esperançoso - nos dão condições de perceber a sua visão integral, positiva, transcendente e aberta, base para um diálogo interdisciplinar com a reflexão ético-teológica. Destacamos que elas estão em relação com outras três que ele mesmo cunhou como importantes na análise crítica, abrangente e interdisciplinar: o mundo, o homem e a sociedade (CALADO, 2001, p. 29). Notamos, portanto, que na complexa e rica perspectiva situa-se a consciência crítica ou conscientização.

Para Freire, não existe "a educação", mas "educações”, ou seja, formas diferentes de os seres humanos partirem do que são para o que querem ser. Basicamente, as várias "educações" se resumem em duas: uma, que ele chamou de "bancária", que torna as pessoas menos humanas, porque alienadas, dominadas e oprimidas; e outra, a "problematizadora", que faz com que elas deixem de ser o que são para serem mais conscientes, mais livres e mais humanas (ROMÃO, 2010, p. 133).

A primeira é formulada e implementada pelos que têm um projeto de dominação dos outros; a segunda deve ser desenvolvida pelos que querem a libertação de toda a humanidade, iniciada na própria subjetividade em vias de se tornar consciência crítica. Deste modo, o pensamento sobre o ensino e a educação em Freire, que propicia a formação da subjetividade e da consciência crítica, depende da reeducação do educador, também um ser inacabado. Entende-se que esta relação professor-aluno, fundamental no processo de ensino, é um mecanismo a ser construído de forma lenta na cotidianidade docente, devendo superar a relação de medo e submissão

${ }^{13}$ Cf. ZITKOSKI, 2010, p. 115-117. Para este autor, a originalidade de Freire está na superação de uma forma de pensar totalizante da vida, pois ele busca construir crítica e criativamente novos elementos para conceber a vida humana em sociedade de modo radicalmente democrático e libertador ao elaborar uma nova visão epistemológica a partir da produção do conhecimento de forma dialógica, intersubjetiva e dialeticamente aberta para o dinamismo da vida, a diferença e o inédito viável, além de inspirar profundas inovações na visão política e ética dos problemas que desafiam o mundo atual. 
que, por sua vez, está inserida em um contexto sociocultural particular, que é condicionador, mas não determinante ${ }^{14}$.

Em Freire, o diálogo e o amor ${ }^{15}$, base para o processo educacional, conferem a dignidade humana, fonte da ética e dos direitos. A afetividade, no projeto pedagógico e antropológico freiriano, ocupa um lugar muito importante, pois à medida que a pessoa (o oprimido ou a vítima) vai se conscientizando, vai sendo capaz de ser autônomo e sentir a realidade. $\mathrm{O}$ ensino e a educação, de todo modo, estão intrinsecamente relacionados à sua importante concepção de consciência crítica, pois somente por meio de um lento processo de ensino crítico, profundo e existencial é possível a emancipação dos sujeitos envolvidos.

A educação jamais pode prescindir da formação ética. Em Freire, as relações humanas, particulares e universais, partem da simples constatação de que a educação deve servir a este primado do humanum, chegando a dizer que "nunca me foi possível separar em dois momentos o ensino dos conteúdos da formação ética dos educandos" (FREIRE, 1997, p. 106). Enquanto espaço de formação humana, a educação é

${ }^{14}$ Dussel (2000, p. 438-439), quando analisa o pensamento ético-crítico de Freire no que se refere ao medo da liberdade, percebe que esta condição dos oprimidos, que vivem uma impossibilidade ontológica de serem sujeitos da libertação, deve-se ao fato de que a vítima, o oprimido, acha-se em um primeiro momento "bloqueado" pulsionalmente para se abrir ao mundo da crítica. A hipótese de Dussel é a de que Freire tenha sido influenciado - sendo um sucessor - da primeira Escola de Frankfurt. Ideia semelhante, a partir de uma hermenêutica psicológica e psicanalítica, se encontra em Erich Fromm no seu livro 0 medo à liberdade (1970). Nos três primeiros capítulos, (“A liberdade - um problema psicológico?”; "O aparecimento do indivíduo e a ambiguidade da liberdade" e "Os dois aspectos da liberdade para o homem moderno"), Fromm avança e substitui a orientação puramente biológica de Freud, destacando que por trás da liberdade e do medo há outras situações complexas, tais como: 0 isolamento do homem, as relações impessoais que ele mantém com seu semelhante, a sua alienação, podendo levá-lo a renunciar à liberdade tão penosamente conquistada, fazendo-o desejar um estado todo-poderoso e a consequente sujeição a um líder. Esta sua perspectiva e a de Freire são atuais e relevantes em momentos como o nosso de buscas fundamentalistas e identitaristas (expressão minha), como medo diante do enfrentamento da realidade da vida com suas contradições e conflitualidades.

15 Segundo Rossato (2010, p. 129), o diálogo e o amor não podem ser confundidos com certa tendência de domesticação da consciência, afetivamente passiva e acrítica. Para ele, o diálogo e o amor se opõem a um processo através do qual se cria uma consciência passiva de submissão tanto a pessoas como a um sistema, seja social, seja econômico ou educacional. Esta pode levar a uma perda da subjetividade, fazendo com que a pessoa perca a capacidade de construção de um pensamento crítico, abrindo mão de sua palavra de si, sobre sua história, sobre o mundo. 0 diálogo e 0 amor são a própria conscientização ocorrendo e transformando a pessoa e o seu entorno.

Rev. Pistis Prax., Teol. Pastor., Curitiba, v. 11, n. 1, 077-096, jan./abr. 2019 
essencialmente um processo de conquista e desenvolvimento da dimensão ética. O processo educativo é, na verdade, uma forma sublime de garantir que a dignidade da pessoa, balizada nos direitos humanos, seja consolidada mediante a própria consciência do sujeito envolvida criticamente no próprio processo.

Constata-se, então, que a educação é na sua essência um encontro ético entre o eu e o outro. Sem ética é impossível efetivar um projeto de educação libertador e humanizante. Para Freire, a ética, enquanto o esforço de humanização e convivência respeitosa com todos os seres, deve ser a grande orientadora de todo o processo educativo, quando provoca as consciências na busca pela verdade e as opressões introjetadas ${ }^{16}$ que impedem a emancipação do sujeito.

Portanto, no atual contexto, a autonomia e a emancipação do sujeito são valores inerentes à cultura educacional que conquistaram espaço em todas as teorias pedagógicas contemporâneas. Para o filósofo e pedagogo Paulo Freire, o processo educativo e o ensino não se reduzem à figura do educador, mas são fruto do protagonismo criativo, crítico e corajoso do discente, quando é ajudado no seu processo de emancipação.

\section{Considerações finais}

A reflexão aventada no título "Teologia e Direitos Humanos: um diálogo interdisciplinar entre Tomás de Aquino e Paulo Freire na perspectiva da consciência" propôs-se a fazer dialogarem dois autores de contextos distintos. O tema do ensino e da educação em ambos os autores, com ênfase na ideia de um "humanismo", apresenta acentuações importantes e particulares que apontam valores a serem colocados em diálogo e assim estabelecer uma proposta de formação da subjetividade e da consciência.

Partindo da ideia segundo a qual educar é um ato propriamente humano, ético, empenhativo e em construção, encontramos tanto em

${ }^{16} 0$ tema da introjeção e extrojeção em Freire é sempre pertinente e profundo. Em Pedagogia da Esperança (FREIRE, 1994, p. 106), ele analisa o fato de que "é possível compreender o fenômeno da introjeção do opressor pelo oprimido, a aderência deste àquele, dificuldade que tem o oprimido de localizar o opressor fora de si, oprimido". 
Tomás como em Freire um humanismo bem solidificado. A teologia, sendo uma ciência que interpreta a realidade à luz das suas fontes específicas, hoje, em uma perspectiva interdisciplinar e também pluridisciplinar, é chamada a dialogar com outros saberes. No caso, a educação, aprendendo a inserir a conflitualidade e a discursividade em seu horizonte de compreensão. Este caminho ainda é complexo, porém possível. Aqui, foi proposta uma reflexão entre um teólogo e um pedagogo que, em síntese, tratam acerca do ser humano.

Em Tomás, o paradigma filosófico e ontológico, centrado na ideia de ser, apresenta um forma de compreender o ser humano, a ética e o processo de ensino (aprendizagem) a partir de uma racionalidade de cunho metafísico-naturalístico, enquanto, em Paulo Freire, a abordagem é assumidamente fenomenológico-hermenêutica, buscando compreender as relações de poder e a política que influenciam a consciência do sujeito. Entre Tomás e Freire há a confiança na inteligência do sujeito, capaz de ser um autoconstrutor da própria subjetividade, mediante um lento processo de formação que exige a capacidade interior de se abrir ao universo exterior. O horizonte de mundo dos dois pensadores foi marcado pela pluralidade de perspectivas e abordagens, com correntes de pensamento específicas, exigindo sínteses e reflexões ousadas.

A formação da consciência em Tomás e Freire está em estreita relação com suas visões de ser humano, educação, ética e mundo. Para ambos, pensar de forma a reproduzir um status quo ou manter uma ideia não se sustenta. Em Tomás, com as questões disputadas, vislumbra-se um jovem teólogo e intelectual assumindo, com coragem e racional análise, as grandes controvérsias universitárias e sociais, exigindo uma síntese dialética. Em Freire, há a insistência em ensinar e educar a pensar a partir da realidade concreta do aluno, visando a lenta e gradual passagem de uma consciência ingênua ou mágica para uma visão crítica da realidade. A subjetividade, na verdade, aparece neles como uma construção interior e exterior do sujeito, envolvido nas tramas e conflitos em que vive.

Na cultura atual, marcada pela emergência de novas subjetividades, imersas na grande indústria de massa, anestesiadas pela cultura do consumo e pensamento frágil, em meio a certo fundamentalismo com nuances de neoconservadorismo religioso e moral, Tomás e Freire podem ser 
repropostos como modelos teórico-práticos que apresentam, cada um a seu modo, a busca incessante pela verdade humana e divina. Diante de um cenário em que alguns discursos ideológicos emergem e conquistam emocionalmente as consciências, vemos como urgente buscar um fundamento sólido no diálogo interdisciplinar sobre os direitos humanos com o intuito de recentrar a dignidade da pessoa humana em sua própria condição de constante aprender tanto a ver a verdade e a realidade como também a interpretá-la.

Tanto a verdade humana (para Freire) como a compreensão de uma fé verdadeira (em Tomás) exigem a mobilidade da inteligência. Enquanto a inteligência (subjetividade em construção), em sua complexa realidade, não é totalmente assumida, terá sempre um constante processo de aprendizado a ser realizado pela pessoa, seja na condição de docente ou discente.

O pensamento de Tomás de Aquino e o de Paulo Freire, no que se refere ao ensino e educação, são pertinentes, relevantes e atuais diante de certa tendência educacional ou formativa que, ao invés de propiciar a busca pela emancipação do sujeito mediante o desenvolvimento das suas potencialidades, tende a manter a pessoa em uma complexa e sutil forma de anestesiamento de sua consciência (TORREL, 2008, p. 383) ou suprimi-la diante da responsabilidade do livre pensar.

\section{Referências}

ANDREOLA, B. Engajamento. In: STRECK, D. R. (org.). Dicionário Paulo Freire. Belo Horizonte: Autêntica, 2010.

AUER, A. Morale autonoma e fede cristiana. Milano: Edizioni Paoline, 1991.

BEDNARSKI, F. A. L'educazione dell'affettività alla luce della psicologia di S. Tommaso D’Aquino. Massimo/Milano: Studia Universitatis S. Thomae in Urbe, 1986.

BRANDÃO, C. R. Paulo Freire: educar para transformar. São Paulo: Mercado Cultural, 2005. 
CALADO, A. J. F. Paulo Freire: sua visão de mundo, de homem e de sociedade. Caruaru: FAFICA, 2001.

CASTELLS, M. Galassia Internet. Milano: Feltrinelli, 2013.

CHENU, M.-D. Introduction a l'étude de Saint Thomas d'Aquin. Deuxième Édition. Paris: Librairie Philosophique J. Vrin, 1954.

COLOMBU, M. Il fine dell'educazione secondo i principi di San Tommaso. In: CONGRESSO INTERNAZIONALE TOMMASO D'AQUINO NEL SUO VII CENTENARIO. L'UOMO, 1974, Napoli. Atti... Napoli: Edizioni Domenicani Italiane, 1974. p. 426-438.

COMPAGNONI, F. Direitos Humanos. In: COMPAGNONI, F.; PIANAN, G.; PRIVITERA, S. Dicionário de Teologia Moral. São Paulo: Paulus, 1997. p. 222-229.

COSTA, J. S. Tomás de Aquino. A razão à serviço da fé. São Paulo: Moderna, 1993.

DUSSEL, E. Processo ético-crítico em Paulo Freire. In: DUSSEL, E. Ética da libertação na idade da globalização e da exclusão. Petrópolis: Vozes, 2000. p. 427-443.

FREIRE, P. Educação como prática da liberdade. Rio de Janeiro: Paz e Terra, 1975a.

FREIRE, P. Pedagogia do oprimido. Rio de Janeiro: Paz e Terra, 1975b.

FREIRE, P. Ação Cultural para a liberdade e outros escritos. Rio de Janeiro: Paz e Terra, 1982.

FREIRE, P. Conscientização: teoria e prática da libertação: uma introdução ao pensamento de Paulo Freire. São Paulo: Moraes, 1980.

FREIRE, P. Educação e mudança. Rio de Janeiro: Paz e Terra, 1985.

FREIRE, P. Pedagogia da esperança: Um reencontro com a Pedagogia do oprimido: Rio de Janeiro: Paz e Terra, 1994.

FREIRE, P. Pedagogia da autonomia: saberes necessários à prática educativa. Rio de Janeiro: Paz e Terra, 2013.

FREIRE, P.; MACEDO D. Alfabetização. Leitura do mundo. Leitura da palavra. Rio de Janeiro: Paz e Terra, 1990. 
FREIRE, P.; SHOR, I. Medo e ousadia. O cotidiano do professor. Rio de Janeiro: Paz e Terra, 1997.

FROMM, E. O medo à liberdade. Rio de Janeiro: Zahar, 1970.

GRANDINETTI, A. L'attualità della pedagogia metodologica tomistica nel "De Magistro". In: CONGRESSO INTERNAZIONALE TOMMASO D'AQUINO NEL SUO VII CENTENARIO. L'UOMO, 1974, Napoli. Atti... Napoli: Edizioni Domenicani Italiane, 1974. p. 464-466.

JOSAPHAT, F. C. Tomás de Aquino e Paulo Freire: pioneiros da inteligência, mestres geniais da educação nas viradas da história. São Paulo: Paulus, 2016.

JESUS, R. M. Paulo Freire pedagogo e filósofo. In: CARDOSO, D. (org.). Pensadores do século XX. São Paulo: Loyola; Paulus, 2012.

LAUAND, L. J. Tomás de Aquino. Sobre o ensino (De Magistro). Os sete pecados capitais. São Paulo: Martins Fontes, 2004.

LE GOFF, J. Os intelectuais na Idade Média. Rio de Janeiro: José Olympio, 2003.

LE GOFF, J.; SCHIMITT, J.-C. Dicionário temático do Ocidente Medieval II. Bauru: Edusc, 2006.

LUENGO, G. C. Tomás de Aquino testigo y maestro de la fe. Salamanca: San Esteban, 1999.

MARITAIN, J. Filosofia moral: Examen histórico-critico de los grandes sistemas. Madrid: Ediciones Morata, 1962.

MIZUKAMI, M. G. N. Ensino: as abordagens do processo. São Paulo: Editora Pedagógica e Universitária, 1986.

MONDIN, B. Dizionario enciclopedico del pensiero di S. Tommaso d'Aquino. Padova; Edizioni Studio Domenicano, 1991.

MONDIN, B. La metafisica di Tommaso D’Aquino e i suoi interpreti. Bologna: Edizioni Studio Domenicano, 2013.

MORIN, E. Por uma reforma do pensamento. In: PENA-VEGA, A.; NASCIMENTO, E. P. (orgs.). O pensar complexo. Edgar Morin e a crise da modernidade. Rio de Janeiro: Garamond, 1999. 
ROMÃO, J. E. Educação. In: STRECK D. R. (org.). Dicionário Paulo Freire. Belo Horizonte: Autêntica, 2010. p. 133-134.

ROSSATO, R. Práxis. In: REDIN, E.; STRECK, D. R.; ZITKOSKI, J. J. (orgs.). Dicionário Paulo Freire. 2. ed. Belo Horizonte: Autêntica, 2010. p. 129-130.

THOMAE AQUINATIS. Questiones Disputatis: De Veritate: De Magistro. Q. 11, art. 1-4. Romae: Marietti, 1964. p. 223-233. (Versão latina).

TOMÁS DE AQUINO. Suma de Teologia. São Paulo: Loyola, 2002.

TOMÁS DE AQUINO. Sobre o ensino (De magistro) e Os sete pecados capitais. Tradução e estudos introdutórios Luis Jean Lauand. São Paulo: Martins Fontes, 2004. (Clássicos).

TORREL, J.-P. Iniciação a Santo Tomás: sua pessoa e obra. São Paulo: Loyola, 2004. TORREL, J.-P. Santo Tomás de Aquino: mestre espiritual. São Paulo: Loyola, 2008. TORRES, C. A. Diálogo e práxis educativa: uma leitura crítica de Paulo Freire. São Paulo: Loyola, 2014.

WEISHEIPL, J. A. Frère Thomas d'Aquin: sa vie, sa pensée, ses oeuvres. Paris: Les Éditions Du Cerf, 1993.

WEISHEIPL, J. A. Tomás de Aquino: vida, obras y doctrina. Pamplona: Eunsa, 1994.

ZITKOSKI, J. J. Dialética. In: STRECK, D. R. (org.). Dicionário Paulo Freire. Belo Horizonte: Autêntica, 2010.

Recebido: 07/01/2019

Received: 01/07/2019

Aprovado: 11/03/2019

Approved: 03/11/2019 